\title{
Commentary: STS of the Underground
}

\author{
TREVOR BIRKENHOLTZ \\ UNIVERSITY OF ILLINOIS
}

\begin{abstract}
Geographer Trevor Birkenholtz draws out major themes across the articles in the thematic collection "Engaging the Underground: An STS Field in Formation," with reference to cartographic and model production and representation, particularly in the ways that they render the landscapes partially knowable and contestable.
\end{abstract}

\section{Keywords}

STS; expertise; underground resources; modeling

\section{Introduction}

This STS of the Underground ESTS Thematic Collection is breaking new ground in both the fields of STS, as well as in critical social science research on underground resources. In STS scholarship, historically, the underground has been a place to advance theoretical concerns (social construction; co-construction of science and politics; network theories such as ANT; boundarymaking and assemblages), rather than as an object of study in and of itself. The papers in this thematic collection show the degree to which the underground-mining, groundwater, mineral exploration--and the expertise(s) that bring these objects into being are worthy of study due to their unique empirical and agential properties that also destabilize and complicate our theoretical concepts.

The papers likewise inform, challenge, and advance the many social scientific accounts of underground resources, including hydrocarbons (Huber 2013), groundwater (Birkenholtz 2008; Sultana 2013) and minerals (Bridge 2004). The focus of this body of work has been on the politics of extraction (Perreault 2013; Bebbington et al. 2008); questions of appropriation (Watts 2016); scarcity and security (Cordell and White 2015); hazards (Cutter, Boruff and Shirley 2003); expertise (Horowitz 2010; Birkenholtz 2008); commodification and marketization (Hurley and Ari 2011); and their materiality (Bakker and Bridge 2006).

The papers in this thematic collection combine many of the insights from these two bodies of literature to explain the complex technoscientific machinations and social processes (in

. Trevor Birkenholtz, Email: trevbirk@illinois.edu

Copyright (C) 2018 (Trevor Birkenholtz). Licensed under the Creative Commons Attribution Non-commercial No Derivatives (by-nc-nd). Available at estsjournal.org. 
the Latourian sense) that bring underground resources into being. Some of the papers also expand upon and inform research from critical cartographies (Crampton and Krygier 2005). Collectively, the articles in this thematic collection advance an understanding of an "STS of the Underground" in at least three ways. First, the papers elucidate the histories of underground exploration and the way they accumulate over time like a palimpsest. In doing so, they elucidate how these histories of exploration, knowing, and rendering legible are embedded in complex political economies of knowledge (Sismondo 2010). Second, they demonstrate the tensions between local and technical expertise that make these processes possible. Here, resources do not simply exist but are brought into being through multiple knowledges, and highly contested modeling and mapping processes that render them legible. In doing so, they show how these efforts and these knowledge(s) are not politically neutral but are reflective of society. And finally, the papers combine insights from STS and critical social science, generally, to explore the degree to which these power struggles over representation and modeling outcomes, like uncertainty, have implications for social power and justice, political representation, and the distribution of environmental and material harms and benefits.

\section{Complex Histories: Political Economy of Underground Exploration and Knowing}

A particular thread in STS research has focused on the political economy of knowledge as it pertains to development in the Global South (Adas 1989; Cozzens et al. 2008). Much of this work has concentrated on the process of knowledge transfer and expertise from the so-called core to the periphery, and the conflicts it creates (Hecht 2002). The papers here advance this body of work by demonstrating the hybridization of technical and local expertise in spaces in the periphery, and the way that they migrate back to the core. In doing so, they destabilize these dichotomous categories and re-center expertise as agency to so-called peripheral spaces. They go onto explain that these local knowledges not only make discovery possible but also demonstrate the degree to which technical/colonial knowledge relies on local expertise in hybrid ways.

This is no more evident than in the process of "discovery." In her paper, d'Avignon demonstrates how the "discovery" of gold in the Sabodala gold mine in southeastern Senegal is a layered historical process that has to do with vernacular communities passing down knowledge and "transferring" it to mostly western experts who then "developed" the deposits. This began during the French colonial period when French geologists would rely on local artisanal miners for cartographic aid. Then beginning in the 1960s, after Senegal gained independence, exploration continued in earnest. It was funded by the Senegalese state with the aid of mainly European and Russian experts. But these projects were "shelved" in the 1970s due to low global gold prices. The 2000s witnessed an upswing in the global gold market. This led to growing interest from international mining investors and the Sabodala mine was re-opened for bidding. The Canadian firm, Teranga, ultimately took over the mine in 2012, subsuming its "exploration permit and research data." Throughout this entire process, spanning from the mid $20^{\text {m }}$ century to the present, local Mande clans' mineral knowledge and use rights were systematically expunged. In tracking this development, d'Avignon animates these historical processes of discovery and valorization of 
previous research and knowledge, while also showing its contemporary significance for existing populations in the area. She then ties these to the prospects for local people in staking claims to past, present, and future resources. The Sabodala case clearly illustrates the degree to which mineral knowledge and prospecting expertise are embedded in a global political economy of knowledge.

In a similar vein, Kneas identifies a fascinating contradiction around mineral reserves in Ecuador, namely the transformation of the country from being supposedly "mineral poor" in the 1960s to proclamations in 2016 by the Ecuadorian government that the country sits on vast deposits of porphyry copper. In this turnabout, the state relied on recent studies completed by the Prospectors and Development Association of Canada (PDAC), which argue that the country is $90 \%$ unexplored. Along with state agencies, PDAC believes that the country sits on vast deposits. In his paper, Kneas addresses the question of what can account for that transformation.

The answer rests with the evolution of plate tectonic theory and state-led modernization efforts. In the 19 century, geological cartographers developed the theory of "Andean Uniformity" whereby it was posited that the Andes are uniform and rich in minerals from Chile to Colombia. But then, in the early $20^{\text {m }}$ century, American geologists contradicted these claims, instead arguing for "Andean heterogeneity." They claimed that Ecuador was largely unexplored and that claims to uniformity were unsubstantiated.

Geological thinking evolved through the late 20" century. This resulted in a rethinking of plate-tectonic theory, which once again raised the possibility of Andean uniformity. The scientific advancements in plate-tectonic theory coincided with two further simultaneous processes. First, rise of Canadian "junior" mineral exploration firms, with financial backing from the Toronto Stock Exchange, were looking to exploit new sites of mineral wealth. Second, the Ecuadorian state was attempting to attract inward investment in the mining sector and reclaim its place as a mineral rich Andean country.

Taken together, the case for Ecuadorian mineral wealth has re-emerged within a specific political economy of knowledge, embedded in state-led extractive industry ambitions. In excavating this history, Kneas demonstrates the links between the state/capital and knowledge, where the state and firms have an interest in advancing claims of mineral abundance. The Ecuadorian state, along with PDAC, marshaled not only advances in plate tectonic theory and the hunger of Canadian financial interests for new sites of investment and potential capital accumulation, but also "uncertainty" in these "recent theorizations of porphyry copper." Both the state and investment-seeking private firms exploited the inherent uncertainty in the models of mineral abundance and in the potential returns.

In a similar vein, Kroepsch examines the political use and scientific adjudication of "uncertainty" in groundwater modeling and property claims. Kroepsch demonstrates how the historically and highly contested landscape of groundwater rights has infused modeling efforts to adjudicate competing knowledge claims around groundwater flow, availability, and assertions over its use. Kroepsch's paper is driven by the question "how and why it is that our improved ability to 'see' underground has not generated epistemic consensus about subterranean space." She posits that groundwater models act as "world builders" that not only represent the non- 
human world, in this case groundwater, but also produce it. In doing so, they simultaneously mask the complex political, economic, and ecological relations that underpin them.

In her paper, she highlights the "inscrutability of the subsurface," which enables competing claims and theories to have particular sway in the adjudication process of claims making. Empirically, the article draws the case of the Fruitland (groundwater) Formation in Colorado to show how groundwater models produce "competing representations of subsurface nature," which then "unevenly embed and enact subsurface politics." She demonstrates how contrasting theories and models of groundwater dynamics produce scientific unknowns or uncertainty that lead to or undermine new policy formation via "adversary modeling." These competing models are used to identify hydrogeological unknowns for which more data are needed, leading to further model development and refinement, but also often more uncertainty. In doing so, she then illustrates how uncertainty is leveraged by differently situated stakeholders to fit their perspectives. This clearly has legal and governance implications. She also effectively demonstrates that this is a recursive process involving groundwater knowledge, uncertainty, governance, and advances in modeling. The process itself, as well as its outcomes, produces new spatial relations on the surface due to the rewriting of groundwater related legal instruments. The relationship demonstrated here between the surface and sub-surface also animates the fourth paper in the thematic collection.

Cumming takes us to Southern California in the first few decades of the 20th century to demonstrate how the production of surface spatial relations is based on subsurface geology. This period was a time when the prospect and discovery of oil in and around Los Angeles was remaking that space. He shows how processes of discovery and prospecting were wrapped up in efforts of social exclusion and capital accumulation. Indeed, the process of oil exploration and extraction in the Los Angeles Basin, which began in 1900, had by the 1930s, destroyed the values of many properties in the vicinities of extraction. Black communities were marginalized, denied access to housing credit and the direct benefits of the oil boom, and yet they bore the brunt of the negative externalities of oil production. This occurred through a mapping process that rendered property regulations weak in non-white residential spaces (see next section). This mapping process was underwritten by various local and expert knowledges.

In his paper, Cumming is particularly adept at highlighting the degree to which the past bears on the present and future. Specifically, he lays bare the links between the various expertise(s) that link oil extraction, real estate speculation, and residential segregation. These processes relied on the actively accumulating knowledge of hydrocarbon engineers, local informers who were working with appraisers, and industry scientists, whose findings of increased cancer risk in areas of petroleum extraction were suppressed. Here the production of expertise was embedded in a complex web of political economic relations between the oil industry engineers and scientists, the real estate industry, and local residents (including homeowners, realtors and lenders).

Smith and Smith carry forward many of the insights from the two previous papers by analyzing underground uncertainty and surface-subsurface co-production. To do so, they focus on the process of "commensuration"- the process of rendering objects comparable with respect 
to various forms of valuation. Drawing on recent work on commensuration, they are able to show the linkages between engineering accounts of risk focused on the subsurface and applied scientists' accounts of risk focused on surface implications. In their article, they draw on primary ethnographic data generated via interviews with engineers and applied scientists across a range of industries and seniority to highlight the process of translation through which surface and subsurface risk is mediated and adjudicated.

In fleshing out the process of translation, they draw on Erin Cech's (2013) concept-the "ideology of politicization" (where engineers view their work and actions as apolitical)—to characterize the social and material process of commensuration/translation through which engineers communicate risk and uncertainty to the general public who may be affected through mining activities. The engineers and applied scientists did this through mapping and modeling, which I return to below. Smith and Smith's key finding inverts this "ideology of politicization," by demonstrating that rather than rejecting the political nature of their work, engineers actually embraced it. Here I quote: "Yet in our research we found that community conflicts did not inspire practicing engineers and applied scientists to shore up and take shelter within the ideology of depoliticization and the social/technical dualism on which it depends, as scholars have noted for other industrial conflicts." Instead, these conflicts prompted them to "consider the subsurface and surface as interlinked, mutually dependent and, in some cases, mutually constitutive." The paper effectively demonstrates the links between "above ground" and "below ground risk," by putting these into dialogue to challenge the often-assumed existing links between hydrocarbon development and extraction with capitalism. In doing so, the authors provide points of entry that may yield less risky forms of mining.

In recounting these complex histories of hybrid ways of knowing the underground and rendering it legible, the authors demonstrate how advances in both method and theory are influenced by contemporary social events and problems. They further demonstrate that we must understand these efforts to know and render legible with respect to the broader processes of the political economy of knowledge, global flows of capital, and state modernization efforts. Evolving techniques of knowing have been central to this nonlinear process. Next, the five papers in this thematic collection make significant contributions to our understanding of the role of modeling, mapping, and legal technologies in rendering underground resources known and legible.

\section{Expertise(s): Modeling, Mapping and Legal Technologies}

$\mathrm{d}$ 'Avignon begins from the position that maps have a long history as tools of empire as a form of rule and control. But she moves beyond previous work that has demonstrated the way that statebased understandings of space and mapping imposed new ways of ordering space onto populations, to an understanding of mapping as an emergent property. In d'Avignon's rendering, mapping is a contested enterprise that emerges out of struggles between prospectors, experts, mining laws, shifting gold prices, new exploration and extraction techniques, and local expertise. In short, she demonstrates that mapping of minerals and underground resources to 
produce the landscape as known and exploitable has always been a collaborative process. It involves local experts and their accumulated knowledge. This process entails a series of discursive and material machinations, moving from drawing board, to shelf, and to the field. It is likely that the sedimentation and mixing of these knowledges and their palimpsest character is rendered visible in the maps they produce.

Kneas also advances previous scholarly understandings of the role of mapping and exploiting mineral reserves in the Global South by unpacking the actors involved in this nonlinear historical process. Here he demonstrates how state, geological, and international experts incorporated, translated, and resolved competing geological knowledge claims. He places these processes within a context of evolving scientific understanding and the complex state power / political economy of Ecuador, including its modernization. Most importantly, he demonstrates how these debates around mineral abundance and mining potential are transforming the country even in the absence of existing mining operations. In doing so he shows how specific forms of knowing--data, models, mapping, exploration, sampling, local expertise-were enrolled into this spatio-temporal process of transformation from mineral poor to mineral rich.

Kroepsch, as noted above, examines the problem of "inscrutability of the subsurface" in groundwater flow systems and the need to render these known and predictable in order to assign rights over the use of groundwater. To address this gap between knowledge of groundwater's materiality and the legal system that adjudicates rights, groundwater models are innovated and then pitted against each other. The process of "adversary modeling" is then used to produce various groundwater flow scenarios that groundwater experts draw on to make the case for their ability represent reality. But in doing so, the models themselves, as well as their human advocates, produce the very groundwater flow reality of use rights that they claim to represent. In both the Kneas and the Kroepsch articles, plate-tectonic models and computer-based modeling, respectively, render legible geological and groundwater processes, but in only partial ways. These models produce uncertainty rather than ameliorate it, which creates an interstice that allows government and private actors to facilitate international investment in the former and to argue for a lack of understanding and business as usual in the latter.

Next, Cumming illuminates a different but no less important form of formal technological knowing. He focuses on the role of legal technologies, in particular the Rule of Capture, which allows oil to be pumped at will by private landowners. The Rule of Capture states that private property owners have exclusive access to underground resources (e.g., oil or groundwater) beneath their land, but that the resource itself is not a private property until it is drawn to the surface. Then, because oil or groundwater does not follow surface property boundaries but rather has an interconnected/interconnecting flow, one landowner may legally extract as much of a resource as they desire, even to the point of diminishing a neighbors' resource. This produced a scramble for oil exploitation in early 20" century Los Angeles that was underwritten by sophisticated property maps. Here, knowing the surface arrangement of land ownership was critical in enabling below-ground extraction. These maps were evolving as ongoing exploration led to new understandings of oil's spatially uneven distribution and 
potential well productivity. These maps, moreover, had a radical and ongoing impact on the surface distribution of benefits and harms from oil exploration and extraction.

Smith and Smith show a divergence from previous research that highlights the tensions between above (i.e. social) and below ground risk by showing that engineers and applied scientists turn to integrated mapping and modeling to commensurate notions and foci of risk. These are concerns that had historically been separated from the central concerns of representing the physicality of the landscape in a process of nature-society dualism making.

In sum, cartographic, mineral, and groundwater models not only offer only partial representations of the world but also produce the world represented. In doing, so models may render landscapes legible but they also produce uncertainty; it is by looking to this uncertainty that questions of power, agency, and social justice emerge.

\section{Knowing is Not Politically Neutral: Representation, Social power, and Justice}

These accounts of exploration, discovery, knowledge hybridization, and modeling bear themselves out in contemporary struggles over truth claims and rendering resources legible in particular ways.

d'Avignon, for instance, demonstrates how the decades-long process of transforming the Sabodala mine into a known and exploitable resource depended upon the simultaneous valorization of local mineral knowledge and its erasure from official accounts. She writes: "The process that enabled this rock formation to become legible as a world-class gold deposit was collaborative and contentious." Rendering it invisible to contemporary experts continues to undermine laborers and the distribution of benefits.

This also occurs in the Kneas piece, in that historically state led exploration, knowledge generation, and discovery were subsidized by the state only to be taken over by Canadian mining firms. While the state may reap some benefits from giving out mining leases, locally affected populations will bear the brunt of environmental externalities.

Kroepsch shows how models confer and deny standing to people and water in groundwater disputes; in other words, how models "serve as 'world builders' both under the ground and above it." The author concludes by asking a much larger and more trenchant question, which is increasingly being lost in the debate about data, expertise and governance: what kind of world ought to be built? This is a normative question that has significant implications in the increasingly arid and hydrologically uncertain American West.

Cumming connects the links between oil extraction and real estate speculation, and the segregation that ensued was both driver and outcome of racial and environmental inequality, as black and Latino families live disproportionately near petro-chemical refineries. So, while they bear the costs of these negative externalities (e.g., cancer-causing benzene leaks, subject to corporate cover-ups), they are reaping none of the direct benefits. Moreover, these populations have been systematically marginalized by federal lending programs through redlining processes that ensured they would be unable to move away from these areas. This occurred in tandem with 
institutionalized insecurity in terms of guaranteeing weak property controls of these groups, allowing for continued contamination by the petro-chemical industry.

The Cumming narrative is one of the co-production of oil and exclusion, of producing the surface and sub-surface simultaneously. While much of the environmental justice literature describes the patterns of environmental injustice, Cumming describes its production, the patterns that are produced, and the interests they serve

Finally, Smith and Smith's conclusion-that those concerned with the underground and those concerned with above ground relations can work together to commensurate their differences towards better outcomes-has major implications for policy and political tactics. The papers demonstrate that knowledge of the underground is embedded in social processes and reflects particular aspects and patterns of society. But in these processes of knowing, claims making, and adjudication are opportunities for resistance.

\section{Conclusion}

This is an inspiring set of papers that is sure to challenge ways of thinking about and studying the underground in both the social sciences and STS. It is also likely to motivate a new generation of scholars to examine the underground as an object of study. These five papers stake out a vibrant research agenda in an emerging field of "an STS of the Underground."

Moving forward, the articles in this thematic collection challenge us 1) to engage the production of expertise and forms of knowing by producing new, competing and/or complementary forms of knowledge of complex underground materialities; 2) to create new metaphors for explaining and describing these phenomena to supplant existing signifiers (such as stock, resource, replenish, etc.); and 3) to study experts and formal modeling techniques in order to become conversant in the language of modelers.

Taken together the articles point to the crucial work that is needed to advance how we think about risk, uncertainty, and societal implications of the underground. Addressing the above points, scholars of an "STS of the Underground" will be positioned to help reconstruct the worlds in which they want to live.

\section{Acknowledgement}

I am grateful to Abby Kinchy, Roopali Phadke, and Jessica Smith for inviting me to participate in the NSF-funded workshop on STS Underground, hosted by the Colorado School of Mines. I would also like to thank the workshop participants, and especially the five authors in this special issue, for sharing their ideas with me and for allowing me to participate in their scholarly process. Finally, my humblest appreciation goes to Katie Vann, Managing editor with Engaging Science, Technology, and Society, for her patience and for her timely support in helping me to finalize this commentary. 


\section{Author Biography}

Trevor Birkenholtz is a cultural and political ecologist, and development geographer. His work attempts to link the political economy of access to and control over environmental resources, and ecological change (political ecology), to issues of technology, knowledge, and social power, more typical of research in science and technology studies (STS).

\section{References}

Adas, M. (1989) Machines as the Measure of Men. Science, Technology and Ideologies of Western Dominance, 15.

Bakker, K. \& G. Bridge (2006) Material worlds? Resource geographies and thematter of nature'. Progress in human geography, 30, 5-27.

Bebbington, A., L. Hinojosa, D. H. Bebbington, M. L. Burneo \& X. Warnaars (2008) Contention and ambiguity: Mining and the possibilities of development. Development and change, 39, 887-914.

Birkenholtz, T. (2008) Contesting expertise: The politics of environmental knowledge in northern Indian groundwater practices. Geoforum, 39, 466-482.

Bridge, G. (2004) Contested terrain: mining and the environment. Annu. Rev. Environ. Resour., 29, 205-259.

Cech, Erin A. 2013. "The (Mis)Framing of Social Justice: Why Meritocracy and Depoliticization Hinder Engineers' Ability to Think About Social Injustices," in Engineering Education for Social Justice: Critical Explorations and Opportunities, edited by Juan Lucena. New York: Springer. Pp. 67-84.

Cordell, D. \& S. White (2015) Tracking phosphorus security: indicators of phosphorus vulnerability in the global food system. Food Security, 7, 337-350.

Cozzens, S. E., S. Gatchair, K.-S. Kim, G. Ordonez \& A. Supnithadnaporn (2008) Knowledge and development. The Handbook of Science and Technology Studies, 787-811.

Crampton, J. W. \& J. Krygier (2005) An introduction to critical cartography. ACME: An International Journal for Critical Geographies, 4, 11-33.

Cutter, S. L., B. J. Boruff \& W. L. Shirley (2003) Social vulnerability to environmental hazards. Social science quarterly, 84, 242-261.

Hecht, G. (2002) Rupture-talk in the nuclear age: conjugating colonial power in Africa. Social Studies of Science, 32, 691-727.

Hurley, P. T., \& Ar1, Y. (2011). Mining (dis) amenity: The political ecology of mining opposition in the Kaz (Ida) Mountain region of western Turkey. Development and change, 42(6), 13931415.

Horowitz, L. S. (2010) "Twenty years is yesterday": Science, multinational mining, and the political ecology of trust in New Caledonia. Geoforum, 41, 617-626.

Huber, M. T. 2013. Lifeblood: Oil, freedom, and the forces of capital. U of Minnesota Press.

Perreault, T. (2013) Dispossession by accumulation? Mining, water and the nature of enclosure on the Bolivian Altiplano. Antipode, 45, 1050-1069. 
Sismondo, S. 2010. An introduction to science and technology studies. Wiley-Blackwell Chichester.

Sultana, F. (2013). Water, technology, and development: transformations of development technonatures in changing waterscapes. Environment and Planning D-Society \& Space, 31(2), 337-353. doi:10.1068/ d20010

Watts, M. 2016. The political ecology of oil and gas in West Africa's gulf of Guinea: state, petroleum, and conflict in Nigeria. In The Palgrave Handbook of the International Political Economy of Energy, 559-584. Springer. 